$\because$ And FINAL REPORT.

\title{
BUILDING TRUST AND CONFIDENCE IN LABORATORY ES\&H POLICY AND PRACTICES
}

A LANL EMPLOYEE CONFERENCE

Submitted on 22 March 1999

by

The Public Dialogue Consortium 


\section{DISCLAIMER}

This report was prepared as an account of work sponsored by an agency of the United States Government. Neither the United States Government nor any agency thereof, nor any of their employees, make any warranty, express or implied, or assumes any legal liability or responsibility for the accuracy, completeness, or usefulness of any information, apparatus, product, or process disclosed, or represents that its use would not infringe privately owned rights. Reference herein to any specific commercial product, process, or service by trade name, trademark, manufacturer, or otherwise does not necessarily constitute or imply its endorsement, recommendation, or favoring by the United States Government or any agency thereof. The views and opinions of authors expressed herein do not necessarily state or reflect those of the United States Government or any agency thereof. 


\section{DISCLAIMER}

Portions of this document may be illegible in electronic image products. Images are produced from the best available original document. 


\section{TABLE OF CONTENTS}

Executive Summary $\ldots \ldots \ldots \ldots \ldots \ldots \ldots \ldots \ldots \ldots \ldots \ldots \ldots$

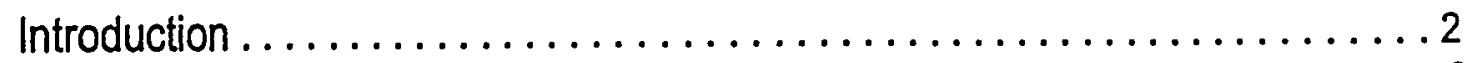

Why a Citizen Conference? ..................................

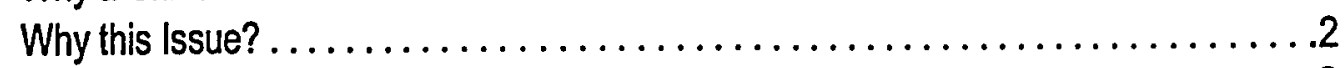

Conference Objectives ...................................... 2

The Conference Issue $\ldots \ldots \ldots \ldots \ldots \ldots \ldots \ldots \ldots \ldots \ldots \ldots, 4$

The Conference Process .......................................

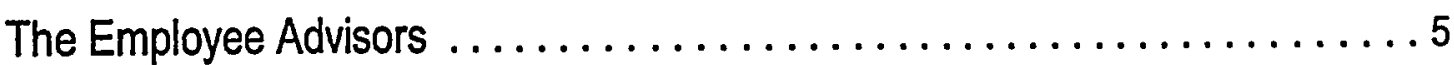

Methods of Recruitment .....................................

The Resource Panel ...................................6

Employee Deliberation and Decision Maker Response ................6-8

Summary of the Deliberation ......................................

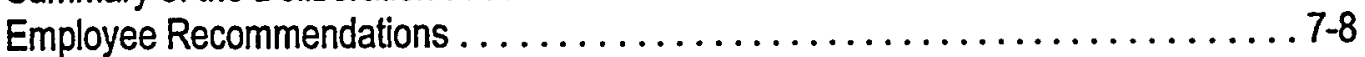

Commitments from Decision Makers ............................... 8

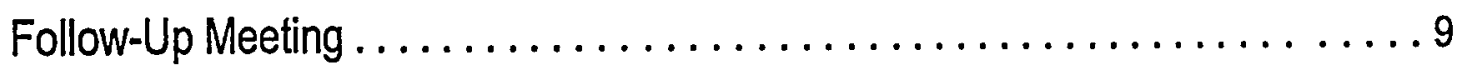

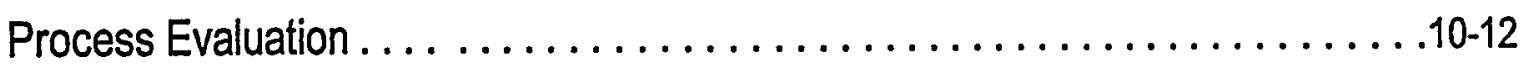

Participant Evaluation ....................................... 10

Staff Reflections and Evaluation ............................. 11-12

PDC Recommendations ............................... 12

Appendix A. Issue Options from the Handbook ..................A1-3

Appendix B. List of Employee Advisors . . . . . . . . . . . . . . . . . A4

Appendix C. List of Resource Persons . . . . . . . . . . . . . . . . A4

Appendix D. List of the Decision Makers . . . . . . . . . . . . . . . . . 4

Appendix E. Selection of Exit Survey Comments .................. A5-8 


\section{Executive Summary}

This report describes a successful pilot event among LANL employees that can serve as a model for employee involvement and community input. The conference was designed to begin building trust and confidence in Laboratory policy and practices in the area of Environment, Safety, and Health (ES\&H). It represents a concrete step toward fostering better relationships among Lab employees and creating a new, innovative approach to communication that can also be used to build trust in the larger community.

Based on the proven methods of the National Issues Forums and the Jefferson Center Citizen Jury Process, this conference enabled management to learn more about the thoughts and advice of LANL employees. During the course of the day, a random sample of Lab employees representing the LANL workforce leamed about issues of health, safety and the environment, and some of the options available to increase trustworthiness in these areas. These "Employee Advisors" then discussed the options at some length and presented recommendations to senior Lab managers in the role of "Decision Makers." At the end of the day, the participants offered their reflections and discussed what they learned during the conference, and Decision Makers responded to what they heard.

The most common view expressed by the Employee Advisors was that a "bottom-up" approach was necessary to develop more relevant ES\&H policies. They were unanimous in their desire for more employee inclusion into the decision making process. All Employee Advisors were in support of a Lab wide survey to determine employee concerns about ES\&H issues.

After listening to the deliberation, the Decision Makers responded with several commitments. The most significant was the pledge to meet with Employee Advisors by the end of February to discuss the status of their recommendations on ES\&H policy and practices.

The ensuing follow-up meeting explored employee concerns in greater depth resulting in forward-looking action steps toward a vision of trust and confidence. The conference and follow-up meeting prompted ES\&H management's decision to initiate positive change. 


\section{Introduction}

Public Interface Design Study (PIDS), is a cooperative effort representing several Divisions within the Lab committed to improving LANL's communication with the public. In their ongoing exploration of better methods of communication, PIDS contracted the Public Dialogue Consortium (PDC) to design and produce an event based on the Citizen Conference model. After thorough review, this prototype conference may be used in the future to obtain high quality input on LANL issues.

\section{Why a Citizen Conference?}

This event was built on the Citizen Conference model, in which citizens deliberate on policy issues and make recommendations on significant public concems. Developed in 1997 by the University of New Mexico Institute for Public Policy, the Citizen Conference model is an innovative form of public meeting adapted from other well- tested formats like the Kettering Foundation's National Issues Forums and the Jefferson Center's Citizen Jury process. What distinguishes the Citizen Conference is its use of representative sampling, a carefully framed issue and a set of realistic policy options, the participation of ordinary community members, a clear presentation of information from diverse perspectives. Unlike most other forums on important issues, the Citizen Conference model allows Decision Makers to tap the wisdom of the community, whose shared and differing values, concerns, and ideas can and should be an important consideration in establishing policy and practice.

This conference centered on the participation by members of the Lab community who were not selected for particular expertise or knowledge about an issue, but for their membership in the community. These "Employee Advisors" were recruited using a stratified random process, to try to ensure a diverse crosssection of the Lab.

\section{Why this Issue?}

PIDS' interest in seeking opportunities for building trust and confidence both with their internal and external communities prompted a desire to hear employee opinions about strengthening trust in Lab ES\&H policy and practices. Another strong inspiration for this topic came from Todd LaPorte's Task Force on Radioactive Waste Management (DOE) and their 1993 report, "Earning Public Trust and Confidence: Requisites for Managing Radioactive Wastes." The Citizen Conference model offered the opportunity to explore this issue and begin to develop trust at the same time.

\section{Conference Objectives}

The PDC and PIDS worked together to develop the primary objectives of the Conference:

- Encourage dialogue between the participants.

- Stimulate creative thinking and positive contributions.

- Create new opportunities for the lab to demonstrate trustworthiness.

- Produce insights on the advantages and disadvantages of options for building trust.

- Generate recommendations for actions that may reasonably be implemented. 


\section{The Conference Issue}

To ensure a productive conference, the PDC worked closely with PIDS to develop first an issue that would be of potential interest to employee advisors within the realm of ES\&H concerns. Then a great deal of effort was put into developing a set of options suitable for an advisor deliberation. The handbook produced by the PDC provided all participants a clear overview of the conference purpose, process, roles, issue, options, and offered process tools for participants. The handbook introduced the advisors to the trust issue:

Trust is essential for any public organization to effectively fulfill its stated mission. Trust is crucial for a cooperative relationship between management and employees. High levels of trust and confidence are also necessary for the legitimacy of any public action. Different perceptions of what public trust and confidence means and how it is demonstrated can lead to reduced trust, the erosion of legitimacy, and seriously damage any bond between a public organization and its constituents.

There are two distinct components of trust trustability and trustworthiness. Therefore, trust is Recognized as a skill as well as a value, and defined by corresponding characteristics of competence and character. If reliability and dependability characterize trustability, then trustworthiness requires honesty, sincerity, and openness.

Trustworthiness is the foundation of trust. It is manifested in sincerity and the honoring of agreements. It can be developed and sustained through strong relationships and reliable actions or through the painstaking crafting of formal contracts designed to avert misunderstanding and provide metrics for ensuring that commitments are met.

Actions taken to ensure a significant reservoir of public trust and confidence may adversely affect other program objectives. Therefore, a careful consideration of all the ramifications of any actions is imperative. If trade-offs, between conflicting goals have to be made, it is important that the stakes be clarified and the balancing of advantages and disadvantages of various approaches be done explicitly.

This conference will focus on building trust and confidence with the intemal Lab community. The following options explore three different approaches to building trust and confidence. Each option highlights current policies and suggests new opportunities for decision makers to further enhance trustworthiness among employees in the areas of Health, Safety and the Environment.

Having provided that introduction, the handbook then defined the specific issue:

How can LANL build trust and confidence with employees in issues related to Health, Safety and the Environment within the Lab?

The three options described were the result of numerous meetings between the PDC and PIDS. Each final option had to meet the following criteria: consider the issue from a distinctly different perspective, include a general overview of existing status, contain factual information, and present new possible opportunities for building trust and confidence. (See Appendix A for Detailed Options) 
Option 1: Increase Access to Information - This option described on-going and new opportunities to build trust in the validity and dissemination of information by providing meaningful information with direct accessibility in real-time.

Option 2: Increased Access to Personnel - This option described existing venues and other possibilities to further build trust \& confidence among employees and decision-makers by making individuals accessible, accountable, and empowered.

Option 3: Renewed Commitment to Health, Safety and the Environment within the Laboratory - This option described the current level of Lab's commitment to ESH and suggests new opportunities to reinforce Safety as a real value, and narrow the gap between its intellectual and operational engagement.

\section{The Conference Process}

The conference began with an orientation and briefing, in which participants learned more about the issues and options and reviewed some process tools, or skills, that would help make the day a success.

During the morning, there were brief presentations by a diverse panel of Resource Persons designed to provide a variety of perspectives, opinions, and ideas relevant to the issue. A Q\&A followed where the Employee Advisors sought to learn more.

After lunch, the Employee Advisors discussed the options and produced a set of recommendations. This was a facilitated discussion of about 3 hours in length in which participants:

- Explored one option at a time.

- Clearly expressed their concerns, values, and interests.

- Talked about what would be gained and lost by each option.

- Generated a set of recommendations.

During this discussion, the Decision Makers and Resource Persons listened intently in another room via closed-circuit television. In their listening role, they were able to:

- Listen to the content of the discussion.

- Think about how employee ideas might be modified or combined in creative ways.

- Hear what common themes are important to the employees.

- Identify the rich differences among employees' perspectives, opinions, and ideas.

- Learn about elements of the Lab culture they might not otherwise have considered.

The Employee Advisors later made a formal presentation of their recommendations. The Decision Makers, audience members, and the LANL press had an opportunity to ask the Employee Advisors about their deliberation and recommendations. At the end of the aftemoon, the Decision Makers took center stage to reflect briefly on what they learned, offer concrete commitments, and discuss next steps. 


\section{The Employee Advisors}

To provide the employee advisors with pertinent information about building trust and confidence issues in area of ES\&H, the advisors were given the aforementioned handbook prior to arriving at the Conference. After reading the handbook, the advisors had a better idea of their role, the issue, and the options on which they would deliberate. The role of the Employee Advisors was to discuss and analyze the issue and any information presented. Their participation provided PIDS with a better understanding of employees' perceptions of the issue, feelings about the issue, and advice about possible future actions.

For the Citizen Conference model to be successful, it was essential that the Employee Advisors represent the diverse views and experiences of the Lab. Accordingly, the advisors were recruited using a method that endures relatively representative random sample of all LANL employees. For the purpose of the Citizen's Conference, 14 Lab employees were recruited for the role of Employee Advisor. One dropped out, leaving a panel of 13.

\section{Methods of Recruitment}

The selection procedure was designed to achieve this target number such that the resulting profile would faithfully reflect important characteristics of the Lab community. Speciically, it was decided that the fifteen would be composed of one GS, two OS, two SSM, four TEC, and six TSM representatives. These numbers were intended to correspond to an actual proportional representation by these categories within the Lab community of $4 \%, 9 \%, 16 \%, 24 \%$ and $48 \%$, respectively (according to demographic information provided by LANL). Furthermore, selection procedures were intended to fairly represent the gender and ethnic characteristics of the Lab. Actual Lab-wide demographics by gender and ethnicity are $67 \%$ male, $33 \%$ female, and $64 \%$ white, $27 \%$ Hispanic.

Recruitment was conducted by randomly sampling a single individual from a target category (i.e., GS, OS, etc.), for the purpose of a recruitment telephone call. Random selection was conducted using a computer generated table of random numbers. If no contact resulted from the call, the procedure was repeated. If contact did result, those declining participation were removed from the sample, and gender and ethnicity information was noted for those assenting. This procedure continued until the a priori number of individuals sought for each category was reached. An acceptable gender and ethnicity profile was approximated quite naturally, and only in the case of the last participant recruited was an attempt made to select from a pool of candidates restricted by specific gender and ethnic considerations. The resulting complement of Employee Advisors was $60 \%$ male, $40 \%$ female, and $73 \%$ white, $27 \%$ Hispanic. One TSM participant was a Graduate RA. In total, approximately 140 phone calls were necessary to achieve the 15-person target, yielding a success rate of $11 \%$. Note that the success rate for public events using this format is much higher because participants are paid to attend.

Prior to the event, those agreeing to participate were contacted by the event sponsors, necessary permissions or notifications were given to supervisors and group leaders upon request, and literature concerning the nature of the Citizen's Conference was distributed. On the morning of the Citizen's Conference, fourteen of fifteen recruits attended and participated fully in their roles, and one individual sent a substitute who failed to complete the session. (See Appendix B for a list of Employee Advisors.) 


\section{The Resource Panel}

The Resource Panel was carefully selected to ensure a wide range of opinions and expertise on various aspects of the proposed approaches to improving trustworthiness in the areas of Health, Safety and the Environment. Their principal role was to present information for the Employee Advisors' consideration.

The panelists were chosen through a process where members of PIDS suggested the names of several possible resource persons. The list was refined with an eye toward diversity of perspective and areas of expertise. Finalists were contacted by phone and letter, and everyone contacted agreed to serve. (See Appendix C for List of Resource Persons.)

\section{Employee Deliberation and Decision Maker Response}

\section{Summary of the Deliberation}

Despite an initial lack of shared commitment to the issue, the employees eventually engaged the issue enthusiastically. At least one employee expressed a lack of clarity on the issue of trust and confidence. There was also some confusion in the beginning on whether the employees should address external or internal trustworthiness. After these uncertainties were cleared up, the panel did go through each option systematically.

\section{Option 1: Increased Access to Information}

In consideration of building internal trust, employees felt that since they already trust the data, an increase in the amount of information was not important. A bigger problem is the day-to-day, face-to-face interactions with management. Employees described a gap between how they are trained to deal with ESH issues and the actual expectations for their work. They want to be included in the process of making decisions about what information is shared or withheld, how they can access that information, and how they can integrate it into their jobs and productivity. Employees want to see a user-friendly system that is clear and accessible, possibly in the form of a multi-media format accessible to all, and one that is supported by management. They expressed the desire for a workable system that avoids unnecessary paperwork, inquisitions, and watchdogs. Common themes that emerged during this discussion include:

- Relevance of information - Provide information relevant to employees.

- Consistency - Need for coherence among various pieces of information.

- Collaboration - Desire for management to work with employees rather than against them.

- Efficiency - Need to avoid proliferation of rules and procedures.

- Clarity and accessibility--Request for user friendly information.

\section{Option 2: Increased Access to Personnel}

Employees called for more workable meetings. Attendance at forums, meetings, and trainings could be boosted by making them more relevant and efficient. Several suggestions were made. Sponsors should make sure the topic is of interest. Employee input on meeting design might be solicited, and feedback should be provided to assure those in attendance that something happened as a result of the meeting. Meetings should include all relevant stakeholders, including contractors and management, and management should indicate a sincere desire to listen and collaborate. Smaller, more focused meetings might encourage employees to participate more. Several themes emerged in the discussion: 
- Inclusion - Desire for inclusion in management decisions.

- Safety - Ability to provide input without threat of retribution.

- Importance/seriousness/presence - Management listen to employees and take them seriously.

- Results/change - Seeing an outcome to employee input.

- Focus/purpose - Seeing a clear purpose and goal for employee involvement.

- Efficiency - Careful weighing of cost of employee participation.

Option 3: Renewed Commitment to Health, Safety, and the Environment

On this option, the employees advocated for a combination of the current external oversight structure and a dedication to common sense. They feel that any approach to Safety should demonstrate an understanding of employees' daily work regime. Safety checklists should be combined with a sincere concern for the worker doing his or her job. Common sense can be exhibited in all the trainings, videos, meetings, and presentations by making them relevant to the worker's specific job. Common sense can also be exhibited by allowing people to take personal responsibility for their decisions and by interpreting policies and regulations rather than passing the buck. The employees feel that inaction leads to gridlock and resentment. The themes that emerged in this part of the deliberation are:

- Responsiveness/decisiveness/responsibility/accountability - Desire for management response to environmental needs, make clear decision and be accountable for them.

- Relevance/need - Making sure that decisions are relevant and necessary.

- Cost/Efficiency - Need to consider the cost of policy and procedures implemented and to make them efficient.

- Simplicity/common sense - Need for parsimonious, sensible solutions.

- Genuine contact/communication - Management show genuine concern and communicate with employees.

A good deliberation will produce such common themes. Just as significant, however, are the rich differences that emerge. A substantive deliberation of representative employees should reflect many voices. In this discussion, for example, employees expressed:

- The desire for clearer direction and reliance on employee judgment.

- The need for more management accountability and the need to avoid "finger pointing."

- The desire for more collaboration and the frustration of time lost in too many meetings.

Employee Recommendations

In general, the Employee Advisors seemed to favor a more relevant "bottom-up" approach. The main recommendations that emerged were:

- Focused job-specific training

- Safety Circles (similar to Quality Circles)

- Lab wide Survey of employees about ES\&H 
Specific recommendations relevant to each option include the following:

\section{Option 1:}

- Survey employees regarding information.

- Provide multi-media outlets for information.

\section{Option 2:}

- Conduct small focused meetings that include all relevant people.

- Provide appropriate feedback to employee on outcomes.

- Make meeting easy to attend; valuing employees time.

\section{Option 3:}

- Make safety practices relevant to the specific work environment.

\section{Commitments from Decision Makers}

Decision Makers as a whole demonstrated that they had listened actively to the employee deliberations. This was evident in the many specific reflections and acknowledgments of actual comments made during that session. Several speakers offered comments consistent with a general theme of active listening recognizing that the Employee Advisors required follow-through in terms of the specific recommendations and general sentiments that were expressed.

The following Decision Maker commitments largely centered on the idea of demonstrating some kind of follow-through.

- ES\&H Division will schedule a meeting at the end of February with the Employee Advisors to discuss the progress of their effort and the impact of their recommendations on future ES\&H policy and procedures.

- ISM will incorporate the Employee Advisor recommendations into a current report on the effectiveness of current ISM policy.

- Others pledged to keep the issues active in future meetings and planning, to study the report of the event, etc.

(See Appendix D for List of Decision Makers) 


\section{Follow-Up Meeting}

The follow-up meeting that occurred on February 24, 1999 proved both valuable and fruitful. Approximately 20 people attended, most of whom were participants in the November 24 Citizen Conference. The meeting objectives were:

- Clarify the Employee Advisor concerns from Citizen Conference

- Build on the Commitments made at Citizen Conference

- Finalize the Citizen Conference Final Report

- Develop next steps for the continuing dialogue, including a decision about a second event

The participants first clarified the concerns from the Citizen Conference. The most important concern for the group is the existence of a "system of retaliation" that exists in the Lab. Consequences of speaking out about issues of concern are great and create an environment of mistrust. Employee advisors also feel that "they are the first community." Only after a trusting environment is developed within the Lab, can LANL begin to work with the outside community (the public). This is not only an ES\&H issue, but is a Lab-wide issue. This lack of trust is exhibited in many ways, which are "sub-concerns" for the advisors, including:

- Irrelevant training

- Training that is too basic

- Overabundant and irrelevant information

- ES\&H solutions are often complex and cumbersome

- Lack of an anonymous method to address concerns

The participants then considered the question:

How does LANL gain the trust and confidence of its employees?

A positive discussion yielded the following recommendations:

- Take personal responsibility to address trust issues. Employees as "good will ambassadors" in the community, building the image of trust with strong role models.

- Understand that earning trust is a long-term endeavor. Trust can be earned by keeping commitments, continuing the dialogue, and being consistent.

- Managers accept this lack of trust as a personal responsibility and challenge. Useful suggestions - the Citizen Conference video, an employee survey.

- Look carefully at methods offered for addressing concerns. "Grassroots" group to work on concerns, ES\&H should hold more internal Citizen Conferences.

- Look carefully at training issues. Training should be job-specific, and include employee contributions.

- Lab-wide retaliation "training" to educate about the many perceptions of retaliation. Training may include selected "retaliation" segments to show mangers, convince the Lab that it is not in their best interest to retaliate, and provide resources to employees who suffer from retaliation.

\section{Commitments from ES\&H:}

- A meeting with Employee Advisors and the "Employee Concerns" group will be arranged.

- Create a video release memo and explore possibilities for using video.

- ES\&H will continue concern with:

- Training issues

- Anonymous method to "voice"

- Tools for managers to see these problems, e.g., showing the video at All Managers Meeting

- Quality communication 


\section{Process Evaluation}

\section{Participant Evaluation}

Thirteen exit surveys were collected. Of these, seven were from Employee Advisors, three from Resource Panelists, and three were from Decision Makers. For each of six survey questions, summary information will be presented regarding the pattern of participants' responses. (A selection of relevant or representative comments from the survey itself can be found in Appendix E.)

The first question asked whether participants (a) had the opportunity to speak, to listen, and to be heard, and (b) their feelings about the value and/or usefulness of their efforts. All participants who answered this question indicated that they did have the opportunity to speak freely and to be heard, and seven felt the overall effort was of value, four felt the effort might be of value, and two did not comment on the usefulness of their participation. Six of eleven individuals stated that they would recommend participation to a peer. There were no recommendations against participation.

Next, participants were asked if the actions, recommendations, and/or proposals that resulted from this conference will meaningfully impact future policy and procedures within the Lab. Five participants answered in the affirmative (two Employee Advisors, two Resource Panelists, and one Decision Maker). Seven stated that policy might change as a result of the conference or that they hoped it would (four were employee advisors), and one individual did not respond. Although optimism and/or hopefulness regarding future change were most frequently qualified, there were no clearly negative responses to this question.

The third question had participants consider whether the Citizen's Conference succeeded in increasing participation in decision-making, how the Citizen's Conference compared with other methods, and whether a superior method was perceived. Although the majority of respondents did not answer this question, those that did agreed that the event successfully increased participation, that it compared more favorably or at least equally to alternative methods, and no superior alternatives were explicitly indicated.

Fourth, respondents were asked if their awareness and/or attitudes regarding the issues under discussion were changed in any way as a result of the conference. Of the seven responses given, six indicated that changes occurred, and three said they had not (Two Employee Advisors, One Panelist).

Participants were also asked to indicate what they liked most about the conference, and how the process might be improved. The Employee Advisors appreciated the opportunity to state opinions and liked the fact that they felt heard. The Decision Makers welcomed the opportunity to be in a listening role, and to observe the deliberations via closed circuit television. The Resource Panelists respondents liked the candid discussion by Employee Advisors and the Decision Makers.

Finally, respondents were surveyed about what they liked least about the event. There were several comments from respondents about the lack of time. Some Employee Advisors and Resource Persons recommended that a survey be used to better define the issue and develop the options. One respondent (Resource Person) would like to see a more coordinated effort for future Resource Panel presentations. 


\section{Staff Reflections and Evaluation}

Several debriefings involving various members of PIDS and PDC were held. In general, we were pleased with the execution and outcome of this event and felt that the Citizen Conference format has promise for community input.

The quantity and quality of participation was remarkable. All of the Resource Persons attended, and their presentations were excellent. Many stayed for the entire day. Only one Employee Advisor dropped out, and the quality of the employees' deliberation was good. The information provided to participants was very substantive. The booklet proved helpful, and employees received a variety of useful information from the presentations.

Although there was some initial confusion about the role of Decision Makers, this group included people in key roles, including the Directors of Environmental Safety and Health and Integrated Safety Management. The Decision Makers were present throughout the deliberation, listened intently, took employee comments seriously, and showed that they were involved by their responses at the end of the day. Our impression was that this both amazed and delighted employees.

Although this event was designed to explore trust and confidence among employees within the Lab, it also served as a prototype for an event that might be held in the community. For this reason, it is helpful to speculate on what might be learned about community trust from the employees themselves. In the context of this conference, the Employee Advisors did not take naturally to the notion that they are simultaneous citizens of the community and Lab employees. We did not explicitly ask them to take this role, and understandably they retained an "internal" focus. We are curious about what employees might have said had we asked them to speak from the perspective of community member or from both perspectives. Would they have answered differently, and if so what would be the implications of this shift in response?

The issue of trust and confidence was framed primarily by PIDS, who acted as representatives of the Lab, with the assistance of the PDC. The question naturally arises: Was this a real issue for employees? Although it was met with initial skepticism, trust and confidence turned out to be a genuine concern of employees. The options did not resonate well with them. Although the ensuing discussion proved fruitful, the quality of the deliberation would likely benefit from more actual employee involvement in the issue framing process.

Some of the listeners were intrigued by the conflicting opinions and ideas presented by employees. On one level, the Employee Advisors were clearly contradictory, and because each employee has a variety of experiences, contradiction is normal. Focusing too much on contradiction, however, may lead some observers to discount the wisdom of what the employees expressed. There are several other, potentially more fruitful ways of understanding differences:

- Differences can be viewed as a rich resource for creative exploration. For example, by discussing contradictory points of view, groups can develop even more insight into a problem and identify in greater detail the values underlying various perspectives.

- Differences can be heard as a shared concern to be addressed. For example, employees may say that management should defer to employees, yet employees need firm directions. Both of these opinions reflect a shared concern for establishing practices that work for employees. 
- Differences can represent openings for defining problems in new ways and solving them creatively. For example, at times the employees seem to call for more accountability in matters of safety, but at other times, they objected to "finger pointing." On one level, this may be a contradiction, but on another it suggests a way to frame the problem: How can people be acknowledged for taking responsibility for matters of safety?

The facilitators did a good job of crystallizing the common themes emerging during the discussion, but they could have better summarized the differences and encouraged engagement in more direct ways as suggested above.

We agree that the press conference proved ineffective, and we now question its necessity for an internal event. We still believe, however, that this is an essential part of any future community event using the Citizen Conference format. The press conference took valuable time that might have been used more productively to extend the Decision Maker responses.

The length of future events is an important consideration. A longer event (e.g., one and a half days) would provide more time.for the development of process tools and interaction between Decision Makers and Employee Advisors, while also increasing cost and recruitment difficulties.

\section{PDC Recommendations}

1. Plan more dialogue events for employees.

2. Based on this prototype event, design and implement a community process for public input.

3. Keep the basic citizen-conference format in tact, but make modifications as necessary to adapt to the public.

4. Get the cooperation of appropriate decision makers from the Lab to attend the entire event and take the "decision maker" role.

5. Provide sufficient time to develop process tolls for all participants.

6. Provide even more time fore the Decision Maker response at the end.

7. Eliminate the press conference feature for internal events, but strengthen it for community events.

8. Now that the pilot event is completed, develop a streamlined method for designing future events.

9. Increase constituent involvement in the issue framing. 


\section{Appendix A. Issue Options from the Handbook}

\section{Option 1: Increase Access to Information}

One aspect of building trust resides with the validity and dissemination of data. LANL's NewNet (Neighborhood Environmental Watch NETwork) is a good example of how raw data retrieved from many locations, and managed by various people, is accessible in real-time. This network of meteorological and radiological monitoring stations with central data storage and processing systems, provides public access to the data via the Internet. This model could also be adapted to address employee concerns about safety issues at LANL and work-related health risks. Some possibilities include:

- A Personnel Radiation Monitoring System, operated by ES\&H that allows LANL employees to directly access accurate and complete real-time data from various radiation monitoring stations. Employees could easily obtain their personal dosimetry information in a confidential user-friendly format, and cumulative data could be stored in weekly and monthly reports for employees. This communication system could also provide an active and confidential Q\&A section where employees can ask more specific questions on a variety of health and safety topics related to their personal results and other radiation safety concerns and issues.

- An Environmental Surveillance Data System which also provides near real-time raw data from the surrounding area. This system could feature Consumer Report style analysis, including impact summaries and trend analyses.

- An on-line inventory of Hazardous Materials that provides up to date information as to the locations and quantities of hazardous substances.

\section{Option 2: Increased Access to Personnel}

- Building trust and confidence among employees and decision-makers can develop when individuals are accessible, accountable and empowered. There are a number of successful communication practices throughout the Lab, as well as between the Lab and the public. Some examples are John Browne's Town Hall Meetings, with Q\&A sessions on safety issues, and the Quarterly Public Meetings sponsored by the Public Interface Design Study (PIDS) which cover an array of topical issues and include Lab employees, government agencies, citizen groups and the general public. Other possible opportunities are:

- An Employee Forum that provides for ongoing dialogue with ES\&H and Lab employees about safe work practices. The board will broadly represent Lab employees from all divisions as well as members of ES\&H. Upon recruitment to the board, all representatives participate in an orientation to the Employee Forum and training sessions that emphasize dialogue communication methods. The board serves as a central forum to discuss current environmental, safety and health issues and helps plan for anticipated health concerns. It may also sponsor quarterly Lab Tours conducted for any interested employee. Possible guidelines: 
- The gatekeepers of the flow of information are accessible to employees;

- The decision makers are accessible, and accountable for their actions and decisions;

- Employees have access to recourse, a system of checks and balances;

- Employees are accountable, they share responsibility and authority for the information they disseminate, their actions, and decisions;

- Employees have an open forum in which their concerns can be heard.

- A new iteration of the now defunct Working Group to Address Los Alamos Health Concerns to consider Safety, Health and Environmental concerns. A proactive approach to meeting and anticipating employees' informational needs about an emerging issue like Beryllium. In addition to educational workshops and seminars on beryllium, other possibilities may include a quarterly newsletter and website to provide timely information and Q\&A.

- Another innovative communication practice is the Citizen Conference model, which has been used with success in other settings. Its flexible format has allowed for shared learning by all participants and for the exploration of numerous topics.

\section{Option 3: Renewed Commitment to Health, Safety and the Environment within the Laboratory}

Safety First! is the primary tactical goal championed by Director John Browne since his tenure began in 1997. It is integrated into all Lab activities through the Integrated Safety Management (ISM) program. The ISM Safety Concern Program is a no fault partnership between any employee and their group-level manager to record and resolve safety problems. The database portion of the program, the Safety Concern System (SCS) strives to enhance communication between any employee and their manager. Director Browne, in his Commitment to ES\&H Memo (April 1998), embraces the Dupont 'Five Zeros' model which presumes all occupational injuries and safety and environmental incidents are preventable. This sentiment is echoed by

Environmental Management's Environmental Stewardship Office recent proposal that the Lab pursue and win the "Governor's Green Zia Excellence Award," which recognizes organizations that successfully minimize their waste and environmental impact. The guiding principle of "Safety as a value not just a priority," underlies this commitment to zero tolerance. A recent assessment of safety leadership and management indicates that the management walk-around process has increased the comfort level for communicating about safety concerns. However, there still exists a gap between the intellectual and operational engagement about safety. Initiatives like Safety Days help create awareness but do not change behavior. While Safety is improving, here are some possible opportunities to keep ISM from being regarded as merely another tolerated bureaucracy: 
- A renewed dedication to educate, train, and motivate employees to understand and help make ISM effective; safety leadership behavior is necessary at every level of the organization. Group leaders need more tools to prove that safety adds value to work.

- Create incentives to help motivate employees, like Annual Individual and Team Recognition Awards, which celebrate safety success stories.

- Emphasize that compliance with this commitment is the responsibility of all employees including contractors acting on the Lab's behalf, and is a condition of all contracts. A separate evaluation of contractor safety to help strong "buy in" from contracting community.

- Establish a website that provides a regular report back to all stakeholders on the Lab's progress toward the zero tolerance goal. A comprehensive presentation of data may include: total recordable injuries; environmental incidents; environmental performance in area of air emissions and water contamination; environmental fines and penalties; and an evaluation of the annual independent ES\&H audit is available for review. This may include the feedback from the safety oversight University of California President's Panel.

- A strong alliance with governments, and policy makers to work on sound policies, laws, regulations, and practices that improve community health and environment. 


\section{APPENDIX B. List of Employee Advisors}

David Alberstein

Catherine Finn

Catherine Hensley

Jerry Lugo

Fred Mortensen

Judith Prono

Jim Rubin

Debra Sandoval

Thomas Short

Denise Tiede

Patricia Vardaro-Charles

Allen Wallace

Lavern (Gary) Wiig

Joseph Zowin

\section{APPENDIX C. List of Resource Panel}

Christina Armijo, Public Affairs

John Bartlit, State Chairman of NM Citizens for Clean Air \& Water; Lab retiree

Ernie Gladney, ESH chemist

Charlotte Lindsey, ESH Information Manager

Bruce J. MacAllister, LANL Ombudsperson

Larry Sanders, Project Leader NEWNET

Philip Thullen, Director of Integrated Safety Program

Elmer C. Torres, Community Relations Office; former Governor of San Ildefonso Pueblo

\section{APPENDIX D. List of Decision Makers}

Denny Erickson, Director of LANL Environment, Safety and Health Division

Phil Thullen,

Linda Anderman,

Lee McAtee 


\section{APPENDIX E. Selection of Elaborative Comments from Exit Surveys}

1) If a co-worker received an invitation to participate in a Citizen Conference and approached you for advice about whether to attend, how would you respond to questions about: (a) having had the opportunity to really speak, to listen, and to be heard, and (b) your feelings about the value and/or usefulness of your efforts.

\section{Employee Advisors:}

"I would tell (a peer) that it was quite worthwhile. I had the opportunity to speak out and participate as much as / wanted."

"The value... will be determined by future actions which I will be looking for. There is no way to answer this question now."

"I felt all the chances I could ask for to speak, listen, and be heard."

"If the Decision Makers take our advice and do something about how we feel..."

"I felt my perception of trust in the lab was quite a bit different than the majority of the group, therefore didn't feel very effective."

Decision Makers:

"The approach has a genuiness about listening, being heard, and speaking."

"Would encourage participation-useful insight-value will or will not be shown with time."

Resource Panelists:

"The value from this is that it may make a difference in the future, as to how things are conducted at LANL."

2) Do you think that the actions, recommendations, and/or proposals that result from this conference will meaningfully impact future policy and procedures within the Lab? If so, why and to what extent? If not, why would you expect there would be no impact?

Employee Advisors:

"Perhaps-we did uncover an underlying problem-but l'm not sure we came up with the solutions. The issue of trust seemed not to be an ESH issue."

"I hope they will but would be very surprised. The present system is strongly entrenched and I'm not convinced that the will exists to change..."

"I am generally optimistic but...it will happen because the decision makers heard some harsh things." 
"Yes-I believe in the sincerity I felt from the group at the end of the session."

"Somewhat. I believe we did not have a good idea as to what the issues of trust were for LANL employees."

"Yes, I feel that changes are blowing over the LANL winds."

"Hard to say-The potential is there...but that is in the hands of decision makers."

Decision Makers:

"Has a chance."

"Yes they can be significant if we can find ways to follow-up \& implement the actions."

Resource Panelists:

"Yes, it seems as though the conference focused on a bottom up approach to ISM, and the lab is trying to do this..."

"If the recommendations are followed through and another meeting of this type is held, then there is a possibility."

3) Think for a moment about the issue of increasing community participation in policy and decision-making and consider all of the ways one might accomplish this goal. Of all of the methods you have seen or can imagine, how does this Citizen Conference compare? Was participation, in fact, meaningfully increased? Do you perceive a superior way to accomplish this goal?

Employee Advisors:

"A good idea and worth a try-I don't have a befter idea."

'Yes (it increased participation, but) find out what the issues of trust are first, then have a conference."

"This approach provides for more extensive dialog than open public meetings, but for less broad based participation."

Decision Makers:

"Balanced representation."

"I think it could be a very useful means."

Resource Panelists:

"I think the citizen's conference is a good tool...(but) I don't think its more valuable than other approaches being attempted but is at least as good." 
"...communication between all people is a must..."

4) Has your awareness and/or attitudes about the issues under discussion today changed in any way as a result of your participation in this Citizen Conference? If so, how? If not, why do you feel this is the case?

Employee Advisors:

"Yes, trying to understand Management's point of view."

"Yes, people have different working experiences at the Lab as far as worker/mgmt interactions go."

"It's nice to know ESH is aware of problems and is trying to change."

"No-Not much new information."

Decision Makers:

"Not really. However, passion of employees reinforces our needs for involvement and participation."

"Yes-It has reinforced my determination to work on employee involvement."

"Reinforced some things-motivated me to try \& do some things."

Resource Panelists:

"Not very much, but I feel that the discussions, recommendations and guidance provided by top management was helpful and encouraging."

"I learned a lot by listening to the employee advisors. I plan to utilize their comments in my project."

5) List three or more things you liked most about this Citizen Conference, as well as any ways the process might be improved.

Employee Advisors:

"The opportunity to state my view and have someone actually listen."

"Everything; More time."

"Facilitation was good."

"The response from Decision Makers at the end."

"It was an interesting exchange of ideas..." 
"Opportunity for open communication."

Decision Makers:

"Opportunity to listen."

"Separating people with the TV seemed to work well."

Resource Panelists:

"The Decision Makers discussion."

"The participation of employees and their honesty and truthfulness."

6) List three or more things you liked least about this Citizen Conference, and most importantly, how these shortcomings might be corrected.

\section{Emplovee Advisors:}

"It took a long time to get started-it wasn't until the end of the resource panel presentations that I began to see what questions panel members had been asked to address."

"Too much to do in just one day. Need more time."

"Find out what the issues of trust are first, then have a conference."

"Not enough time at the end to define issues \& then hear what decision makers have to say."

“...probably tried to do too much in allotted time. Options 1 \& 2 did not fit well into lab citizen discussions."

\section{Decision Makers:}

"Short time for advisors to form recommendations."

"The intro was way too tedious."

\section{Resource Panelists:}

"I think the conference could be improved by conducting a survey to develop the examples."

"The Resource Panel presentation might be enhanced by having its constituents coordinate their presentations so that the goal of the exercise is reinforced and the themes...can be presented with less redundancy.

"Maybe a two day session, with one day focusing on issues and concerns of employees. Second day to have discussions between decision makers to provide recommendations to people in higher positions." 